Marquette University

e-Publications@Marquette

College of Education Faculty Research and

Publications

Education, College of

$10-1-2013$

\title{
Evaluation of a University-Community Partnership to Provide Home-Based, Mental Health Services for Children from Families Living in Poverty
}

Robert A. Fox

Marquette University, robert.fox@marquette.edu

Ryan Mattek

Marquette University, ryan.mattek@marquette.edu

Brittany L. Gresl

Marquette University

Accepted Version. Community Mental Health Journal, Vol. 49, No. 5 (October 2013): 599-610. The final publication is available at Springer: DOI. (C) 2013 Springer Verlag. Used with permission.

Shareable Link. Provided by the Springer Nature SharedIt content-sharing initiative. 


\title{
Evaluation of a University- Community Partnership to Provide Home-Based, Mental Health Services for Children from Families Living in Poverty
}

\author{
Robert A. Fox \\ Department of Counselor Education and Counseling Psychology, \\ College of Education, Marquette University \\ Milwaukee, WI \\ Ryan J. Mattek \\ Department of Counselor Education and Counseling Psychology, \\ College of Education, Marquette University \\ Milwaukee, WI \\ Brittany L. Gresl \\ Department of Counselor Education and Counseling Psychology, \\ College of Education, Marquette University \\ Milwaukee, WI
}

Significant behavior problems occur in $10-15 \%$ of preschoolers (Campbell, 1995) and may be present in up to one third of young children living in poverty (Anthony, Anthony, Morrel, \& Acosta, 2005). These behavior problems usually are sufficiently severe to warrant a psychiatric diagnosis such as oppositional defiant disorder, conduct disorder, attention deficit hyperactivity disorder, separation anxiety 
disorder, or reactive attachment disorder, among others (Keenan \& Wakschlag, 2002). Without intervention, these early behavior problems can persist into the elementary school years and even adolescence (Campbell, 1995; Keenan, Shaw, Delliquadri, Giovannelli, \& Walsh, 1998), with the clear potential to develop into more serious and intractable behavior problems (Breitenstein et al., 2007; Gelhorn, Sakai, Price, \& Crowley, 2007).

A number of treatment programs for young children have emerged that focus on decreasing problem behaviors (e.g., aggression, non-compliance, destructiveness) (Eyberg, Nelson, \& Boggs, 2008). These early intervention programs, which consist largely of cognitive-behavioral procedures that are developmentally appropriate for toddlers and preschoolers, have significantly reduced early childhood behavior problems (Brinkmeyer \& Eyberg, 2003; Nicholson, Anderson, Author, \& Brenner, 2002; Webster-Stratton, 1994). The treatment efficacy research for these early intervention programs is relatively new and initial studies have been conducted in well-controlled, laboratory or clinic-based studies (Lyon \& Budd, 2010). The next and more difficult step is to determine the effectiveness of these treatment programs in community-based, mental health centers that typically serve more at-risk populations of children.

The first challenge to extending the treatment strategies from laboratory research to the community is ensuring that a mental health center or other community-based organizations have personnel who are competent to deliver evidenced-based treatment programs for young children. Unfortunately, most community agencies, including mental health clinics, are often ill-equipped to provide mental health services to young children and families. This finding should not be surprising when considering that graduate programs that offer specialized training for mental health professionals in early childhood issues are rare (Author, Jorgenson, \& Author, 2010). One solution to the absence of appropriately trained professionals in community-based organizations is to consider establishing university-community partnerships (Abdul-Adil, et al., 2010). This model combines the expertise of a university with the mental health staff of a community organization to provide evidence-based practices to families in a real

Community Mental Health Journal, Vol. 49, No. 5 (2013): pg. 599-610. DOI. This article is @ Springer and permission has been granted for this version to appear in e-Publications@Marquette. Springer does not grant permission for this article to be further copied/distributed or hosted elsewhere without the express permission from Springer. 
world setting. Another viable option would be for community agencies to seek specialized training for its mental health staff to begin to meet the needs of a younger population of children (McNeil \& HembreeKigin, 2010). Regardless of what model is chosen to ensure professional competence in delivering specialized treatment programs to young children, a second challenge is applying these evidencebased treatment programs to the at-risk populations typically served by community-based organizations, namely, children living in poverty.

The causes of behavior problems in young children from families living in poverty are complex. Huaqing Qi and Kaiser (2003) cited three domains of risk factors associated with poverty that contribute to the development of problem behaviors in preschool-age children. These risk factors include child characteristics (level of attachment, temperament, social skills, cognitive ability, language development), parent characteristics (parent mental health issues, age, education, parenting style, addictions), and socioeconomic factors (singled headed households, unemployment, multiple children, limited support network, exposure to violence, family instability, lack of resources). A given child's likelihood of developing significant problem behaviors is determined by the number and severity of factors that are operating in a family over time. Consequently, evidence-based treatment programs must have sufficient flexibility to adapt to the unique factors that may be present for a specific child and family for maximal treatment impact.

The purpose of this study is to describe a pilot, universitycommunity partnership to implement an evidence-based treatment program (Author \& Nicholson, 2003) through a community-based agency for young children living in poverty, many of whom also presented with a developmental delay. The university partner was a private university that offered master's programs in community counseling with an emphasis on children and adolescents and a doctoral program in counseling psychology. A faculty member from the university served as the founder and director of the Behavior Clinic (as this partnership subsequently became known) and was provided partial release time from teaching to direct the clinic's activities. In addition, the university provided a research assistant to develop and implement a data base for the clinic and to assist in training graduate

Community Mental Health Journal, Vol. 49, No. 5 (2013): pg. 599-610. DOI. This article is @ Springer and permission has been granted for this version to appear in e-Publications@Marquette. Springer does not grant permission for this article to be further copied/distributed or hosted elsewhere without the express permission from Springer. 
students who served as clinicians along with the community agencies' licensed professional counselors. Master's students from this university as well as other local universities applied for training at the clinic through supervised internships and practica experiences. The community partner was a large Birth-to-Three organization that annually offered a variety of therapy services (e.g., speech, occupational, and physical therapy; special education) to over 1,400 children identified with special needs. This agency was chosen because it had over a 40-year presence in the community and a reputation of providing excellent clinical services to low-income families. This agency provided office space for the Behavior Clinic as well as infrastructure support (utilities, copying/mailing, computer support). For this pilot project, the clinic was funded by grants from several local foundations and a grant from the state. The study also was approved by the university's Institutional Review Board (IRB). Families were not charged for any clinical services. This study reports the outcomes of a two-year effort to provide individual, in-home, parent and child therapy for toddlers and preschoolers from mostly single-parent, loweducated families living in the inner city of a large urban area. As part of this study, we also examined family attrition and followed a small group of children one year after completion of the treatment program.

\section{Method}

\section{Participants}

The participants in this program were 356 children from a large, urban Midwestern city consecutively referred over a two-year period to a university-community partnership clinic developed specifically to address mental health issues in very young children (Author, Keller, Grede, \& Bartosz, 2007). This clinic served as the home base for the staff and was responsible for taking new referrals, providing staff and student training programs, conducting staffing and supervision meetings, writing and storing reports, and taking care of other clinic functions (e.g., staff evaluations, ordering clinic materials). All clinical services from intake to termination and follow-ups were provided by the staff in the homes of the children who were referred for services. Referrals were made by parents or other caregivers (e.g., grandparents, foster parents), individual providers in private practice

Community Mental Health Journal, Vol. 49, No. 5 (2013): pg. 599-610. DOI. This article is @ Springer and permission has been granted for this version to appear in e-Publications@Marquette. Springer does not grant permission for this article to be further copied/distributed or hosted elsewhere without the express permission from Springer. 
(e.g., pediatricians, public health nurses), and over 30 social service agencies, hospitals, schools, and daycare centers. Eligibility criteria for the program included: (a) the child was under six years of age; (b) the referral source expressed significant behavior or emotional concerns for the child such as aggression, destructiveness, hyperactivity, oppositional behavior, separation anxiety and/or self-injury; (c) the child did not have significant physical disabilities, serious medical conditions, or present with symptoms suggesting the possible presence of a Pervasive Developmental Disorder; and (d) the child's parent/guardian signed an IRB-approved consent form. If a parent declined participation in the research project, the same treatment program was offered to the family but their data were excluded from any data analyses.

\section{Procedures}

Referral and intake. A referral form including the referral source, family contact information, and the child's age and referral concerns was required to initiate clinic services. Upon receipt of the completed referral form, parents were contacted to obtain more information about their concerns, to determine the eligibility of the child for the pilot project, to describe the clinic's treatment program, and to explain the important role of the parent/caregiver in treatment. Eligible children were placed on a waiting list to be scheduled for an intake when a clinician had an opening. Parents of ineligible children were provided referrals to other agencies. An initial, two-hour intake evaluation session was conducted that included a review of available records and a comprehensive parent interview to determine the history and current environmental factors that contributed to the child's referral concern. In addition, parents were asked to play with their child as they normally do while rates of children's compliance to parent requests were recorded and the study's self-report measures were completed. The first treatment session was scheduled within a week of the intake.

Treatment program. This study utilized an individualized format of the Parenting Young Children (PYC) Program for young children (Author \& Nicholson, 2003). The PYC Program includes four main treatment elements: (a) strengthening the parent/child 
relationship through non-directive play; (b) helping parents maintain appropriate developmental expectations for their child and learn cognitive strategies to avoid emotionally and behaviorally overreacting to their child's challenging behavior in a negative manner; (c) using techniques to strengthen the child's pro-social behaviors such as positive reinforcement, establishing home routines, and giving good instructions; and (d) employing limit-setting strategies to reduce the child's challenging behaviors such as redirection, ignoring, response cost, and time-out. In the PYC Program, treatment strategies were explained to the parent and directly modeled by the clinician. Parents also practiced each strategy with their children during the treatment sessions and received immediate feedback from the clinician. Handouts were provided to explain treatment strategies in more detail as were all other materials needed to implement the treatment and to maintain a safe environment for the child (e.g., edible and tangible reinforcers, toys, door gates for time-out; safety latches for kitchen cupboards). Families were provided a magnetic reminder card of the next appointment to put on their refrigerators and were given a reminder phone call or card in the mail the day before each scheduled appointment.

The core treatment concepts and skills (child-led play, parent cognitive strategies, maintaining appropriate developmental expectations, procedures for strengthening pro-social behaviors and decreasing challenging behaviors) were covered and an individualized treatment plan was established by the fourth session. The remaining sessions involved further tailoring the treatment plan to the unique strengths and needs of each child such as using active ignoring for tantrums, establishing bed time routines for sleeping problems, and using social reinforcement to teach listening skills. A significant amount of time also was spent problem-solving with families when implementation difficulties arose (e.g., using a time-out in a very small and overcrowded apartment; encouraging siblings and extended family members to assist in treatment delivery). During later sessions, a parent-coaching component was included where clinicians observed parents during their natural day-to-day interactions with their children and provided immediate feedback to parents as they implemented treatment strategies. Finally, the clinicians served an important advocacy role for families and assisted them in obtaining needed 
resources (e.g., a child's bed, referring a child for a preschool program or a special education or speech evaluation, arranging an appointment for the child to see a pediatrician or dentist, referring the parent to have their mental health needs addressed, etc.). Clinicians also were mandated reporters and would contact appropriate agencies for suspected child abuse and neglect.

The treatment program was designed to be completed in eight, once-weekly, treatment sessions; however, often more sessions were needed to meet the treatment goals. All treatment sessions were approximately $1 \frac{1}{2} 2$ hours in length. In addition to the treatment sessions, all participants were encouraged to participate in separate pretest (intake), posttest (scheduled within one week of the final treatment session), and a four-to-six week follow-up evaluation sessions. In addition, a small number of families completed a follow-up evaluation one year following treatment completion.

Clinician training. Clinicians were master-degreed therapists and graduate students in counseling and psychology programs who received practicum and internship course credit for their participation in this study. All clinicians received extensive training and supervision in four modules: (a) working with diverse families of young children with developmental delays who live in poverty and maintaining personal safety in the home setting in unsafe neighborhoods; (b) clinical skills needed for interacting with children less than six years of age and their caregivers; (c) treatment theory, program content and procedures for working with less educated parents from different cultural backgrounds; and (d) assessment administration and data collection. Training included didactic instruction based on a comprehensive training manual, reviewing relevant empirical literature articles, watching treatment program videotapes and rating parentchild interactions to ensure inter-rater reliability, shadowing treatment sessions with veteran clinicians, and a gradual assumption of the role of lead clinician in the field under close supervision. Fidelity to the treatment program was established through the use of specific treatment adherence criteria that were met by all therapists and students prior to their functioning independently as a clinician to ensure consistent administration of the treatment program (e.g., demonstrating sensitivity to families' cultural diversity, tailoring 
language to caregivers' educational levels, establishing and maintaining home visit guidelines, providing caregiver feedback, individualizing treatment strategies to children's needs). Each clinician participated in ongoing weekly supervision (group and individual) for assistance on specific issues that arose with families and for feedback on their performance while implementing the treatment program. In general, clinicians completed training in a period of three-to-four months, at which time they began carrying a caseload of five-to-eight families. As most of the children's homes were located in unsafe neighborhoods, clinicians often provide treatment services in pairs and had access to an on-call supervisor at all times in the event that assistance was required (e.g., evidence of child abuse; caregiver with suicidal ideation). Case assignment was made randomly based on clinicians having an opening in their ongoing caseload to help guard against contamination of the results by possible differences in the level of clinician skill.

\section{Measures}

Three psychometrically-sound, parent self-report measures were applied at the beginning and end of the intervention program, at a four-to-six week follow-up, and for a small segment of the study group, at one year follow-up. The rationale for choosing these measures is that we wanted to obtain an assessment of both the children's challenging behaviors as well as the parents' responses to their children's behaviors. There are relatively few screening instruments available for use with parents of very young children who live in poverty and who tend to have lower reading levels (Holtz \& Author, 2008). The Early Childhood Behavior Screen (ECBS; Holtz \& Author, 2012), a 20-item self-report instrument developed specifically for parents of very young children from low-income backgrounds, measures parent perceptions of their children's challenging and prosocial behaviors. Because the ECBS is a new tool, a second wellestablished measure of children's challenging behaviors was also used - the Eyberg Child Behavior Inventory (ECBI; Eyberg \& Pincus, 1999). The ECBI has been shown to discriminate between problem and nonproblem children for children between two and 16 years of age, and a t-score of 60 has been established as the cut-off score for clinical significance (Weis, Lovejoy, \& Lundahl, 2004). The ECBI has been

Community Mental Health Journal, Vol. 49, No. 5 (2013): pg. 599-610. DOI. This article is @ Springer and permission has been granted for this version to appear in e-Publications@Marquette. Springer does not grant permission for this article to be further copied/distributed or hosted elsewhere without the express permission from Springer. 
shown to be sensitive to changes in problem behaviors in young children following intervention (Author \& Holtz, 2009). The third instrument was the Parent Behavior Checklist (PBC; Author, 1994) that was designed to measure the behaviors (discipline subscale - use of corporal and verbal punishment; nurturing subscale - parent behaviors that nurture a child's health psychological growth) and developmental expectations of parents of very young children (ages 1 to 4 years, 11 months). In addition to these three parent-report measures, a direct observational measure also was included to assess the overall quality of the parent-child relationship. We also measured the child's compliance to a standard set of five parental requests (e.g., pick up the toy, raise your hand) and calculated a compliance percentage score. Two observers independently recorded the total number of parent requests and the total number of times the child complied with the requests for 31 separate observations. The percentage agreement between observers was $96 \%$ for number of parent requests and $100 \%$ for the number of times the children complied. The Diagnostic and Statistical Manual of Mental Disorders (DSM-IV-TR; APA, 2000) was used to provide an overall assessment of the severity of the child's behavior and emotional problems. In order to assist the clinicians in determining a reliable diagnosis for the children, the Kiddie Schedule for Affective Disorders and Schizophrenia for School-Aged Children (K-SADS-PL; Kaufman et al., 1997) was used. Besides the K-SADS-PL proven use with school age children, there also is evidence that it can be successfully applied to younger children. Birmaher et al. (2009) used the K-SADS-PL with a sample of two-to-five year old children and reported strong inter-rater reliability (Kappas $=80-.90)$ and good evidence of convergent, divergent, and predictive validity. Finally we measured the family's satisfaction with the clinical services with a seven-item survey developed for this study. Issues sampled by this survey were related to parent perceptions of their child's improvement, the parent's skills in implementing treatment strategies, and the parents' confidence in managing future behavior issues that may arise. For the present group of participants, the internal consistency for the seven items of the satisfaction survey was $r=.83$.

Community Mental Health Journal, Vol. 49, No. 5 (2013): pg. 599-610. DOI. This article is @ Springer and permission has been granted for this version to appear in e-Publications@Marquette. Springer does not grant permission for this article to be further copied/distributed or hosted elsewhere without the express permission from Springer 
NOT THE PUBLISHED VERSION; this is the author's final, peer-reviewed manuscript. The published version may be accessed by following the link in the citation at the bottom of the page.

\section{Results}

A diagram illustrating the flow of participants through the clinic is shown in Figure 1. Children were placed on a waiting list and contacted for an intake in the order their referral was received. Of the original 356 children referred for services over a two-year period, 109 families could not be scheduled for an intake evaluation (30.6\%). In most cases, the clinic was unable to contact the family (e.g., phone disconnected, family had moved, parent did not respond to voice mails left by the clinician) to schedule an intake appointment (51\%) or when contacted, the parents no longer desired services (29\%). The average wait time between referral and the intake evaluation was 6.74 weeks $(S D=6.71)$. Of the 247 families who completed an intake, 10 were not eligible for inclusion in this study ( 7 refused to sign a consent form but were provided treatment services; 3 did not qualify for services e.g., child was suspected of having autism and was referred elsewhere for services). Of the 237 remaining families, 99 dropped out of treatment before completing the post-treatment evaluation session $(42 \%)$. The most common reasons for early termination included high no-show or cancellation rates $(n=35 \%$; families were terminated from treatment following three unexcused cancellations, caregivers not responding to repeated contacts following a missed session ( $\mathrm{n}=$ $34 \%$ ), and caregivers no longer desiring services ( $n=20 \%$ ); other reasons such as scheduling conflicts and the family moving also occurred.

\section{Comparison of Completers and Non-completers}

Demographic and intake data as well as treatment participation rates for the completers and non-completers are shown in Table 1. Comparisons between these two groups showed that completing parents were older, $t(235)=2.45, p=.015$, were less likely to be married, $X^{2}(1)=8.96, p=.003$, and had fewer children living in their homes, $t(235)=2.84, p=.005$, than noncompleting parents. The majority of children in both groups had one or more developmental delays with speech and language delays being the most common for completers (51\%) and non-completers (44\%). At intake, children from families who completed treatment received lower challenging behavior scores on the ECBS, $t(234)=3.33, p=.001$, as well as lower scores

Community Mental Health Journal, Vol. 49, No. 5 (2013): pg. 599-610. DOI. This article is @ Springer and permission has been granted for this version to appear in e-Publications@Marquette. Springer does not grant permission for this article to be further copied/distributed or hosted elsewhere without the express permission from Springer. 
on the ECBI's intensity scale, $t(235)=2.28, p=.024$, than children who did not complete treatment. The primary referral concern was aggression for children in the completers (46.4\%) and non-completers groups $(54.6 \%)$, followed by serious tantrums (completers $=37.0 \%$, non-completers $=34.3 \%$ ). The majority of children in both groups received a psychiatric diagnosis in addition to having a developmental disability. The most common diagnosis was Oppositional Defiant Disorder for children of completers (71.0\%) and non-completers (75.8\%). Parents of children reported asthma as the most common health concern for completers (23.2\%) and non-completers (21.2\%). The length of time between referral and intake did not differ between completers and non-completers. Completers had more treatment sessions, $t(235)=13.23, p<.001$, spent more time in treatment, $t$ $(235)=6.75, p<.001$, and had higher attendance at treatment sessions, $t(235)=10.72, p<.001$, than non-completers.

\section{Treatment Outcomes for Completers}

Repeated-measures, multivariate analyses of variance were used to assess pretest to posttest, pretest to short-term follow-up, and pretest to long-term follow-up intervention effects for the children and parents in the completers group (see Table 2). When significant time effects were found, univariate $F$-tests were computed to determine the source of the significance. To assess the effect size of the treatment program from pretest to posttest, pretest to short-term follow-up, and pretest to long-term follow-up, Cohen's $d$ (Cohen, 1988) was computed for each dependent variable. Effect sizes were classified as follows: $.2=$ small, $.5=$ moderate and $.8=$ large. The average time between pretest and posttest was 12.88 weeks $(S D=5.47)$, between pretest and the short-term follow-up was 20.78 weeks ( $S D=6.52$ ), and between pretest and the long-term follow-up was 57.56 weeks $(S D=13.04)$.

Child behavior. ECBS ratings for the two subscales of children's behavior showed a significant time effect from pretest to posttest $\left(F_{2,136}=71.41, p<.001\right)$. Following treatment, children's prosocial behaviors increased $\left(F_{1,137}=104.63, p<.001, d=0.70\right)$ and their challenging behaviors decreased $\left(F_{1,137}=105.18, p<.001, d=0.83\right)$. The children made moderate gains in prosocial behavior and large

Community Mental Health Journal, Vol. 49, No. 5 (2013): pg. 599-610. DOI. This article is @ Springer and permission has been granted for this version to appear in e-Publications@Marquette. Springer does not grant permission for this article to be further copied/distributed or hosted elsewhere without the express permission from Springer. 
gains in improving their challenging behaviors. At short-term followup, ECBS ratings for the two subscales of children's behavior showed a significant time effect from pretest to short-term follow-up $\left(F_{2,97}=\right.$ $26.25, p<.001)$. Children's prosocial behaviors increased $\left(F_{1,98}=\right.$ $32.28, p<.001, d=0.65)$ and their challenging behaviors decreased $\left(F_{1,98}=47.41, p<.001, d=0.67\right)$. The children made moderate gains in prosocial behavior and in improving their challenging behaviors from pretest. At long-term follow-up, ECBS ratings for the two subscales of children's behavior showed a significant time effect from pretest to long-term follow-up $\left(F_{2,22}=11.62, p<.001\right)$. Children's prosocial behaviors increased $\left(F_{1,23}=17.67, p<.001, d=0.96\right)$ and their challenging behaviors decreased $\left(F_{1,23}=18.68, p<.001, d=0.62\right)$. The children made large gains in prosocial behavior and moderate gains in reducing their challenging behaviors from pretest. ECBI ratings of children's behavior problems indicated a significant time effect for its two subscales $\left(F_{2,133}=44.45, p<.001\right)$. Following treatment, children's problem behaviors decreased in intensity $\left(F_{1,134}=\right.$ 86.09, $p<.001, d=0.80)$ and were considered less problematic for parents $\left(F_{1,134}=65.0, p<.001, d=0.72\right)$. The gains made were large for intensity and moderate for problems. At short term follow-up, ECBI ratings of children's behavior problems indicated a significant time effect for its two subscales $\left(F_{2,97}=28.15, p<.001\right)$. Children's problem behaviors decreased in intensity $\left(F_{1,98}=50.58, p<.001, d=\right.$ $0.67)$ and were considered less problematic for parents $\left(F_{1,98}=53.31\right.$, $p<.001, d=0.70)$. The gains made from pretest were moderate for intensity and problems. At long term follow-up, ECBI ratings of children's behavior problems indicated a significant time effect for its two subscales $\left(F_{2,23}=8.67, p=.002\right)$. Children's problem behaviors decreased in intensity $\left(F_{1,24}=12.76, p=.002, d=0.77\right)$ and were considered less problematic for parents $\left(F_{1,24}=17.28, p<.001, d=\right.$ $0.91)$. The gains made from pretest were moderate for intensity and large for problems. The percentage of time that children responded to parent requests improved significantly from pretest to posttest $\left(F_{1,120}=\right.$ $60.49, p<.001, d=0.73)$; these gains were moderate. At short-term follow-up, the percentage of time that children responded to parent requests improved significantly $\left(F_{1,89}=54.70, p<.001, d=0.79\right)$; these gains from pretest were moderate. At long term follow-up, the percentage of time that children responded to parent requests improved significantly $\left(F_{1,23}=18.04, p<.001, d=0.46\right)$; these gains from pretest were small.

Community Mental Health Journal, Vol. 49, No. 5 (2013): pg. 599-610. DOI. This article is @ Springer and permission has been granted for this version to appear in e-Publications@Marquette. Springer does not grant permission for this article to be further copied/distributed or hosted elsewhere without the express permission from Springer. 
Parent behavior. Parent ratings for the three subscales of the PBC revealed a significant time effect $\left(F_{3,135}=12.81, p<.001\right)$. Following intervention, parental expectations $\left(F_{1,137}=7.16, p=.008\right.$, $d=0.18)$ and nurturing increased $\left(F_{1,137}=7.75, p=.006, d=0.23\right)$ and parent use of verbal and corporal punishment decreased $\left(F_{1,137}=\right.$ $29.19, p<.001, d=0.46)$. Treatment gains were small for the discipline and nurturing scores and insubstantial for the expectations scores. At short-term follow-up, parent ratings for the three subscales of the PBC revealed a significant time effect $\left(F_{3,96}=14.39, p<.001\right)$. Parental expectations $\left(F_{1,98}=25.89, p<.001, d=0.38\right)$ and nurturing increased $\left(F_{1,98}=17.67, p<.001, d=0.39\right)$ and parent use of verbal and corporal punishment decreased $\left(F_{1,98}=13.13, p<.001\right.$, $d=0.47)$. Treatment gains from pretest were small for all PBC subscale scores. At long term follow-up, parent ratings for the three subscales of the PBC did not reveal a significant time effect $\left(F_{3,22}=\right.$ $2.81, p=.064)$. Parental expectations and nurturing did not change from pretest $(p>.05)$ but parent use of verbal and corporal punishment did change $\left(F_{1,24}=6.74, p=.016, d=0.47\right)$. Treatment gains from pretest were small for all PBC subscale scores.

Clinical significance. Eyberg and Pincus (1999) recommended a t-score of 60 as a cutoff score to determine if the child's scores on the ECBI's intensity and problems scales were clinically significant. The proportion of children who met the ECBI cutoff scores at pretest changed significantly at posttest for the intensity $\left(X^{2}(1)=20.34\right.$, $p<$ $.001)$ and problem scores $\left(X^{2}(1)=18.31, p<.001\right)$. For the intensity measure, $77.0 \%$ met the cutoff criteria at pretest compared to $41.5 \%$ at posttest; for the problem measure, $71.8 \%$ met the cutoff criteria at pretest compared to $42.2 \%$ at posttest. The proportion of children who met the ECBI cutoff scores at pretest changed significantly at shortterm follow-up for the intensity $\left(X^{2}(1)=11.05, p<.001\right)$ and problem scores $\left(X^{2}(1)=8.0, p=.005\right)$. For the intensity measure, $81.8 \%$ of the children met the cutoff at pretest compared to $46.5 \%$ at short-term follow-up; for the problem measure, $75.8 \%$ met the cutoff criteria at pretest compared to $41.4 \%$ at short-term follow-up. The proportion of children who met the ECBI intensity cutoff score at pretest changed significantly at long term follow-up for the intensity score $\left(X^{2}(1)=4.91, p=.027\right) ; 80.0 \%$ of the children met the intensity cutoff score at pretest compared to $44.0 \%$ at long term

Community Mental Health Journal, Vol. 49, No. 5 (2013): pg. 599-610. DOI. This article is @ Springer and permission has been granted for this version to appear in e-Publications@Marquette. Springer does not grant permission for this article to be further copied/distributed or hosted elsewhere without the express permission from Springer. 
follow-up. The proportion of children who met the ECBI problem cutoff score at pretest did not change significantly at long-term follow-up ( $p$ $=.230$ ), in part, due to the relatively small number of participants not meeting the minimum cell size for the chi-square statistic; $80.0 \%$ of the children met the problem cutoff criteria at pretest compared to $44.0 \%$ at long term follow-up.

Family satisfaction. In order to assess caregiver satisfaction with the parent management program, total scores were computed by summing the parent ratings for the seven items comprising this scale with a possible range of scores from 7 (low satisfaction) to 49 (high satisfaction). The average score on this measure was 43.64 ( $S D=$ 4.73).

\section{Discussion}

This study demonstrated that an evidence-based treatment program for behavior problems in young children could be implemented through a university and community partnership in the homes of families living in poverty. The university provided the expertise in evidence-base treatments and graduate students to assist in implementing the treatment program. The Birth-to-Three community agency provided licensed clinicians to participate in learning and implementing the treatment program and supervising students as well as office space and infrastructure support for the mental health clinic. In addition, the agency had a well-established 40year presence in the community which helped families feel comfortable contacting them for needed services. This study also adds to the limited literature on training graduate students to provide in-home, mental health services to at-risk children (Author, Jorgenson, \& Author, 2010). Significant training and supervision were required to expand the university-based counseling and psychology programs that the students received. However, all students and staff were successful in implementing the evidence-based treatment program and four students continued with the clinic following graduation to accumulate the required post-master's supervised hours for licensure.

The outcomes for children completing the pilot treatment program were positive. Children's problem behaviors improved

Community Mental Health Journal, Vol. 49, No. 5 (2013): pg. 599-610. DOI. This article is @ Springer and permission has been granted for this version to appear in e-Publications@Marquette. Springer does not grant permission for this article to be further copied/distributed or hosted elsewhere without the express permission from Springer. 
significantly following treatment based on two parent report measures (ECBS, ECBI) as did the children's compliance to parent requests. These gains were maintained at four-to-six weeks following treatment for the majority of the participants. Moreover, we were able to demonstrate long-term maintenance of treatment gains one year following treatment completion for a much smaller group of participants. These results for our treatment completers are similar to those found in previous well-controlled, laboratory investigations (Eyberg, Nelson, \& Boggs, 2008).

Although we found positive outcomes for children who completed the treatment program, there were significant challenges encountered in implementing and assessing this project. It is important to remember that this was a preliminary, pilot study to determine if a university-community partnership could effectively improve the mental health of very young children living in poverty through a home-based delivery system. Moreover, the literature provided minimal guidance regarding how to proceed in this largely uncharted area. Despite offering our services in the children's homes at times and days convenient to families, we experienced a high attrition rate. We lost $30 \%$ of our participants between referral and intake. In an effort to determine possible causes for this early drop-out rate, we began expanding our referral form to include the ECBS near the end of this project. We collected the ECBS for 31 families who dropped out before an intake could be successfully scheduled. In comparing their ECBS challenging behavior scores $(M=23.81, S D=$ 3.78) with families who either participated in some or all of the treatment sessions (see Table 2 for their ECBS scores), no significant differences between these groups were found $(p>.05)$. Consequently, severity of their children's behavior problems at time of referral did not appear to be a primary issue for dropping out of treatment before intake. In addition, the time between initial referral and scheduling an intake averaged six-to-seven weeks for all participants in this study. However, we also encountered a relatively high variation in waiting times for completers ( $S D=6.49$ weeks) and non-completers ( $S D=$ 6.92 weeks). Despite repeated phone calls and follow-up letters, the length of time between original referral and arranging an initial intake appointment may have taken literally months to arrange. However, given the similarities in waiting time between completers and non-

Community Mental Health Journal, Vol. 49, No. 5 (2013): pg. 599-610. DOI. This article is @ Springer and permission has been granted for this version to appear in e-Publications@Marquette. Springer does not grant permission for this article to be further copied/distributed or hosted elsewhere without the express permission from Springer. 
completers, this variable alone does not appear to account for parents who dropped out prior to an intake evaluation. While some have argued that parent motivation to fully participate in treatment may be at its highest at the time of referral (Barrett, Chua, Crits-Christoph, Gibbons, \& Thompson, 2008; Sherman, Barnum, Nyberg, \& BuhmanWiggs, 2008), the present data suggests that other factors also may be contributing to premature termination. Unfortunately even if time between referral and intake is an important factor for at least some families, there is no immediate solution to this issue. Our clinic has a limited number of qualified clinicians and students and there are few other community providers that exist who can deliver similarlyappropriate services to these very young children. This discrepancy between needed and available services continues to expand as our current waiting list has grown to 80 children. We clearly need to build our community's capacity and corresponding funding levels to meet this growing need of at-risk young children with significant mental health problems.

In addition to the high attrition rate between referral and intake, a significant number of families dropped out before a post-test evaluation could be completed. Following the intake, we experienced a $42 \%$ attrition rate for participants who started treatment but did not complete all sessions or a post-test. Similar high attrition rates have been reported in the literature for similar, at-risk populations (56\% Fernandez, Butler, and Eyberg, 2011; 57\% - Author \& Holtz, 2009). In an effort to identify possible factors that contributed to participant drop-out, we compared families who completed treatment (completers) to those who did not (non-completers). Unfortunately, treatment completers and non-completers were more similar than different from each other on the majority of variables we studied. Our completers were older, less likely to be married, had fewer children at home, and reported less frequent and less intense behavior problems at intake than non-completers. However, these factors alone or even in combination would not be sufficient to determine at intake who would be at risk for early treatment termination. Within a pre and post-test research design, the treatment benefits children may have received in families who dropped out prematurely is not known. In our current work, rather than wait for a post-test evaluation to assess change, we now collect outcome data at each treatment session and been granted for this version to appear in e-Publications@Marquette. Springer does not grant permission for this article to be further copied/distributed or hosted elsewhere without the express permission from Springer. 
can assess a child's progress in treatment on an ongoing basis. We also have front-loaded much of the critical treatment strategies in the first three-four treatment sessions so that the majority of families receive important information and strategies for addressing their children's challenging behavior early in the treatment process. Our preliminary analyses of this data suggest that reliable and significant change in children's challenging behaviors often are evident well before a prescribed number of treatment sessions have occurred, even among families who terminate treatment prematurely.

Challenges continued to be experienced in the present project in obtaining short-term and long-term follow-up results from families who completed the treatment program. Many families were difficult to reach or did not see the value in participating in a short-term follow-up evaluation now that their original referral concerns had been addressed. Regarding the one year follow-up, given the extreme difficulties encountered in locating and contacting families who had completed treatment and arranging an evaluation after this much time had elapsed, we decided to stop this effort after 25 families were evaluated. One contributing factors to locating families was their transient nature. Our families often moved due to evictions and other issues (infested housing, presence of lead). Also we learned that some families would not answer the phone because they were concerned that the call would be from some authority that had identified a concern (e.g., not paying bills); a number of families had their phones disconnected. Many of our families lived day to day and would simply forget a scheduled appointment and not be present when a clinician arrived. Clearly, the subject attrition data throughout all phases of this pilot project raises question about possible selection bias in those who completed the treatment program and raises questions about the generalizability of the results for low income families with young children living in poverty.

We do know that low-income status is one of the best predictors of early drop-out from family treatment programs (Armbruster \& Kazdin, 1994; Lanier et al., 2011). However this finding is less helpful when $95 \%$ of the children served by our clinic come from low-income homes. A more fruitful line of research has been to identify possible barriers that could interfere with their treatment completion (Kazdin \&

Community Mental Health Journal, Vol. 49, No. 5 (2013): pg. 599-610. DOI. This article is @ Springer and permission has been granted for this version to appear in e-Publications@Marquette. Springer does not grant permission for this article to be further copied/distributed or hosted elsewhere without the express permission from Springer. 
Wassell, 1999). These barriers include lack of transportation, inconsistent work schedules, disagreements between caregivers in child rearing philosophies, child illness and medical appointments, caregiver's hope for financial gain such as social security income from a child diagnosis, multiple caregivers, deficient parenting knowledge and skills, reliance on corporal punishment, and parent mental illness, to name a few. One way to efficiently identify these barriers is to include a treatment barrier assessment at the time of referral. Beyond this initial assessment, such barriers could begin to be addressed while also providing the treatment services for the children in the family's homes (Snell-Johns, Mendez, \& Smith, 2004). An in-home setting is particularly appropriate for addressing behavior problems in younger children for several reasons. First, it eliminates many logistical problems common to low-income families seeking therapy services including difficulty maintaining appointments, reliable transportation, and problems finding appropriate child care (Boggs et al., 2004). Second, the in-home setting provides the clinician with a unique perspective into the lives of these very young children in the settings and systems in which they live. Gaining such a view of the child's world would not be possible in a more traditional clinic office setting. Moreover, effective treatment for child behavior problems requires changing parenting practices which can be done most effectively through in vivo instruction and coaching in the home environment.

This study represents one of the first efforts to combine the resources of a university and a community-based agency to address the mental health needs of very young children living in poverty in their home settings. In the absence of a control group or more rigorous research design, it is difficult to attribute the positive results obtained to only the treatment program. As such, this pilot study's primary contribution may be its heuristic value in encouraging others to consider working with this at-risk and young population where these early mental health issues are likely to remain and escalate over time without intervention. The lives of these young children are clearly compromised and more rigorous research is needed to discover the best practices for meeting the needs of this challenging population.

Community Mental Health Journal, Vol. 49, No. 5 (2013): pg. 599-610. DOI. This article is @ Springer and permission has been granted for this version to appear in e-Publications@Marquette. Springer does not grant permission for this article to be further copied/distributed or hosted elsewhere without the express permission from Springer. 
NOT THE PUBLISHED VERSION; this is the author's final, peer-reviewed manuscript. The published version may be accessed by following the link in the citation at the bottom of the page.

\section{References}

Abdul-Adil, J., Drozd, O., Irie, I., Riley, R., Silas, A., Farmer, A.D. Jr., \& Tolman, P.H. (2010). University-community mental health center collaboration: Encouraging the dissemination of empirically-based treatment and practice. Community Mental Health Journal, 46, 417422.

American Psychological Association. (2000). Diagnostic and statistical manual of mental disorders (4th ed. text revision). Washington, D.C.

Anthony, B. J., Anthony, L. G., Morrel, T. M., \& Acosta, M. (2005). Evidence for social and behavior problems in low-income, urban preschoolers: Effects of site, classroom, and teacher. Journal of Youth and Adolescence, 34, 31-39.

Armbruster, P. \& Kazdin, A. E. (1994). Attrition in child psychotherapy. Advances in Clinical Child Psychology, 16, 81-108.

Axelson, D. A., Goldstein, B. I., Monk, K., Kalas, R. N., ... Brent, D. A. (2009). Schedule for Affective Disorders and Schizophrenia for School-Age Children (K-SADS-PL) for the assessment of preschool children - A preliminary psychometric study. Journal of Psychiatric Research, 43, 680-686.

Barrett, M. W., Chua, W., Crits-Christoph, P., Gibbons, M. B., \& Thompson, D. (2008). Early withdrawal from mental health treatment: Implications for psychotherapy practice. Psychotherapy Theory, Research, Practice, Training, 45, 247-267.

Birmaher, B., Ehmann, M., Breitenstein, S. M., Gross, D., Ordaz, I., Julion, W., Garvey, C., \& Ridge, A. (2007). Promoting mental health in early childhood programs serving families from low-income neighborhoods. Journal of the American Psychiatric Nurses Association, 13(5), 313320.

Boggs, S. R., Eyberg, S. M., Edwards, D., Rayfield, A., Jacobs, J., Bagner, D., et al. (2004). Outcomes of parent-child interaction therapy: A comparison of treatment completers and study dropouts one to three years later. Child \& Family Behavior Therapy, 26, 1-22.

Brinkmeyer, M. Y., \& Eyberg, S. M. (2003). Parent-child interaction therapy for oppositional children. In A.E. Kazdin \& J.R. Weisz (Eds.). Evidenced-based psychotherapies for children and adolescents (pp.204-223). New York: Guilford.

Campbell, S. B. (1995). Behavior problems in preschool children: A review of recent research. Journal of Child Psychology \& Psychiatry, 36, 113149.

Cohen, J. (1988). Statistical power analysis for the behavioral sciences (2nd ed.). Hillsdale, NJ: Lawrence Earlbaum Associates.

Community Mental Health Journal, Vol. 49, No. 5 (2013): pg. 599-610. DOI. This article is @ Springer and permission has been granted for this version to appear in e-Publications@Marquette. Springer does not grant permission for this article to be further copied/distributed or hosted elsewhere without the express permission from Springer. 
NOT THE PUBLISHED VERSION; this is the author's final, peer-reviewed manuscript. The published version may be

accessed by following the link in the citation at the bottom of the page.

Eyberg, S. M., Nelson, M. N., \& Boggs, S. R. (2008). Evidence-based psychological treatments for children and adolescents with disruptive behavior. Journal of Clinical Child and Adolescent Psychology, 37(1), 215-237.

Eyberg, S. M., \& Pincus, D. (1999). Eyberg Child Behavior Inventory and the Sutter-Eyberg Student Behavior Inventory-Revised. Lutz, FL: Psychological Assessment Resources, Inc.

Fernandez, M. A., Butler, A. M., \& Eyberg, S. M. (2011). Treatment outcome for low socioeconomic status African

American Families in Parent-Child Interaction Therapy: A pilot study. Child \& Family Behavior Therapy, 33, 32-48.

Author (1994). Parent behavior checklist. Austin, TX: ProEd (Currently available from the Author, Marquette University, School of Education, P.O. Box 1881, Milwaukee, WI 53201-1881;

Email:robert.Author@marquette.edu).

Author \& Holtz, C.A. (2009). Treatment outcomes for toddlers with behavior problems from families in poverty. Child and Adolescent Mental Health, 14, 183-189.

Author, Keller, K. M., Grede, P. L., \& Bartosz, A. M. (2007). A mental health clinic for toddlers with developmental delays and behavior problems. Research in Developmental Disabilities, 28, 119-129.

Author, \& Nicholson, B. C. (2003). Parenting young children: A facilitator's guide. Longmont, Colorado: Sopris West.

Gelhorn, H. L., Sakai, J. T., Price, R. K., \& Crowley, T. J. (2007). DSM-IV conduct disorder criteria as predictors of antisocial personality disorder. Comprehensive Psychiatry, 48, $529-538$.

Harwood, M., \& Eyberg, S.M. (2004). Effect of therapist process variables on treatment outcome for parent-child interaction therapy. Journal of Clinical Child and Adolescent Psychology, 33, 601-612.

Holtz, C. A. \& Author. (2008). Infant mental health: An emerging field for children with developmental disabilities. In A. F. Rotatori, F. E. Obiakor, \& S. Burkhart. (Eds.), Autism and developmental disabilities: Current practices and issues (pp. 163-219). United Kingdom: JAI Press, Emerald Group Publishing Limited.

Holtz, C.A., \& Author, R.A. (2012). Behavior problems in young children from low-income families: The development of a new screening tool. Infant Mental Health Journal, 33, 82-94.

Huaqing Qi, C., \& Kaiser, A. P. (2003). Behavior problems of preschool children from low-income families: Review of literature. Topics in Early Childhood Special Education, 23(4), 188-216.

Kazdin, A. E., \& Wassell, G. (1999). Barriers to treatment participation and therapeutic change among children referred for conduct disorder. Journal of Clinical and Child Psychology, 28, 160-172.

Community Mental Health Journal, Vol. 49, No. 5 (2013): pg. 599-610. DOI. This article is @ Springer and permission has been granted for this version to appear in e-Publications@Marquette. Springer does not grant permission for this article to be further copied/distributed or hosted elsewhere without the express permission from Springer. 
Kaufman, J., Birmaher, B., Brent, D., Rao, U., Ryan, N., Flynn, C., \& Moreci, P. (1997). The Revised Schedule for Affective Disorders and Schizophrenia for School Aged Children: Present and Lifetime Version: Preliminary reliability and validity data. Journal of the American Academy of Child and Adolescent Psychiatry, 36, 980-988.

Keenan, K. Shaw, D., Delliquadri, E., Giovannelli, J., \& Walsh, B. (1998). Evidence for the continuity of early problem behaviors: Application of a developmental model. Journal of Abnormal Child Psychology, 26(6), 441-454.

Keenan, K., \& Wakschlag, L. S. (2002). Can a valid diagnosis of disruptive behavior disorder be made in preschool children? American Journal of Psychiatry, 159, 351-358.

Lanier, P., Kohl, P. L., Benz, J., Swinger, D., Moussette, P., \& Drake, Brett. (2011). Parent-child interaction therapy in a community setting: Examining outcomes, attrition, and treatment setting. Research on Social Work Practice, 21, 1-10.

Lyon, A. R., \& Budd, K. S. (2010). A community mental health implementation of parent-child interaction therapy (PCIT). Journal of Child and Family Studies, 19, 654-668.

Author, Jorgenson, E.T., \& Author. (2010). Home-based therapy for young children in low-Income families: A student training program. The Family Journal: Counseling and Therapy for Couples and Families, 18, 189-194.

McNeil, C. B., \& Hembree-Kigin, T. L. (2010). Parent-Child Interaction Therapy (2nd Ed.). New York: Springer.

Nicholson, B. C., Anderson, M., Author, \& Brenner, V. (2002). One family at a time: A prevention program for at-risk parents. Journal of Counseling and Development, 80, 362-371.

Sherman, M. L., Barnum, D. D., Nyberg, E., Buhman-Wiggs, A. (2008). Predictors of preintake attrition in a rural community mental health center. Psychological Services, 5, 332-340.

Snell-Johns, J., Mendez, J. L., \& Smith, B. H. (2004). Evidence based solutions for overcoming access barriers, decreasing attrition, and promoting change with underserved families. Journal of Family Psychology, 18, 19-35.

Webster-Stratton, C. (1994). Advancing videotape parent training: A comparison study. Journal of Consulting and Clinical Psychology, 62, 583-593.

Weis, R., Lovejoy, M. C., \& Lundahl, B. (2004). Factor structure and discriminative validity of the Eyberg Child Behavior Inventory with young children. Journal of Psychopathology and Behavioral Assessment, 27, 269-278.

Community Mental Health Journal, Vol. 49, No. 5 (2013): pg. 599-610. DOI. This article is @ Springer and permission has been granted for this version to appear in e-Publications@Marquette. Springer does not grant permission for this article to be further copied/distributed or hosted elsewhere without the express permission from Springer. 